\title{
"We'll be Scratching all the Time"
}

\section{Understanding the Role of Language in Computational Thinking Education for Elementary Teachers}

\author{
Heather Killen ${ }^{\dagger}$ \\ University of Maryland \\ College Park, MD USA \\ hkillen@umd.edu \\ Kelly Mills \\ Digital Promise Global \\ Washington, DC USA \\ kmills@digitalpromise.org
}

\author{
Merijke Coenraad \\ University of Maryland \\ College Park, MD USA \\ mcoenraa@umd.edu
}

\author{
Diane Jass Ketelhut \\ University of Maryland \\ College Park, MD USA \\ djk@umd.edu
}

\author{
Lautaro Cabrera \\ University of Maryland \\ College Park, MD USA \\ cabrera1@umd.edu
Jan Plane
University of Maryland
College Park, MD USA
jplane@cs.umd.edu

\begin{abstract}
School systems globally have begun to integrate computational thinking (CT) practices into elementary teaching and learning standards to provide young students with a comfort for and foundational understanding of computer science. This integration requires educating teachers to develop and implement $\mathrm{CT}$ learning opportunities. Our work contributes to best practice by exploring the role language plays in elementary teachers' discussions and development of CT-infused science lessons. To do this, we captured and analyzed the language used by elementary teachers as they spoke and wrote about CT in a multi-week professional development experience during which the teachers created and delivered CT-infused lessons to their students. We determined that teachers exhibited differing CT conceptualizations, which we categorized from broad to narrow. These differences were not, however, observed in either their spoken or written language. While there were instances of teachers using language that mirrored how the facilitators discussed CT, this use did not align with how they conceptualized CT. Our work analyzing connections between CT language use and CT conceptualization suggests that in order to understand how teachers are conceptualizing CT, professional development designers and teacher educators should focus on creating opportunities for teachers to employ CT practices in context rather than relying only on language. We feel this will support a more precise and nuanced engagement with CT.
\end{abstract}

\section{CCS CONCEPTS}

- Social and Professional Topics $\rightarrow$ Computing Education $\rightarrow$ Computational Thinking

Permission to make digital or hard copies of part or all of this work for personal or classroom use is granted without fee provided that copies are not made or distributed for profit or commercial advantage and that copies bear this notice and the full citation on the first page. Copyrights for third-party components of this work must be honored. For all other uses, contact the Owner/Author.

SIGCSE '20, March 11-14, 2020, Portland, OR, USA.

(c) 2020 Copyright is held by the owner/author(s).

ACM ISBN 978-1-4503-6793-6/20/03.

DOI: https://doi.org/10.1145/ 10.1145/3328778.3372667

\section{KEYWORDS}

Computational Thinking, K-8, Computing across the curriculum

\section{EXTENDED ABSTRACT}

There is a growing belief that CT is not only a fundamental skill needed to study computer science but is useful for understanding concepts beyond computing. CT can be outlined very broadly however, allowing for numerous definitions involving a variety of language. Our team presented a CT framework in non-technical language (based on previous work done with $\mathrm{CT}$ and science education) during a 4-month CT professional development experience for teachers. Our framework highlighted four CT practices: Data, Simulations, Programming, and Systems Thinking from a Computational Thinking Perspective. Each session presented a CT practice through activities based in inquiry science instruction, followed by discussion and brainstorming about how to integrate these CT concepts into teacher practice.

We are interested in how elementary school teachers speak and write about infusing CT into their science teaching practice and how well, if at all, the language they use when speaking and writing about CT reflects how they conceptualize CT.

We draw on three sources of data: CT-infused science lesson plans authored by the teachers, teacher reflections on how CT was integrated into those lessons, and focus group transcripts. We find that teachers use framework mirroring language more often when writing than when talking about $\mathrm{CT}$ and that their language differs by CT practice. We found variability in how teachers conceptualize CT but when we aligned those broad to narrow conceptualizations to language use, no measurable patterns were seen.

All teachers used similar language when asked to reflect on CT but applied CT concepts differently. Therefore, relying on the language teachers use when discussing CT abstractly, such as asking them how they might integrate CT into their teaching practice, will not help researchers understand the variability present in the way a group of teachers conceptualize CT. 